Author: Michael Fascia

Research Fellow, Edinburgh Multicultural Research Institute

November 2021

\title{
Viewpoints of Epistemic Principals between Knowledge and Information
}

\author{
Dr Michael Fascia.
}

\begin{abstract}
We can consider the unity of knowledge in a business context as a singular event, but nonetheless, deliberate a contrary perspective from current knowledge transfer practitioners. Both perspectives agree, deliverable knowledge is key for business success and competitive advantage but question the problematic transfer of knowledge. This discussion examines the creation of knowledge, recognised within contemporary writings as significant in determining a starting point for analogous scrutiny, and asks if this focal point is inherently difficult to establish and measure? We then look to synthesise the foremost principal of 'knowledge', which helps underpin congruent knowledge transfer theories, perspectives and doyennes from an occidental business perspective.
\end{abstract}


This will focus on the role of a aspects of information related to knowledge viewpoint within a known knowledge transfer status of business communities. This positioning is significant as it highlights the prominence of epistemic doctrines surrounding aspects of information related to knowledge, but still within a knowledge transfer scenario in a business context. This underpinning is also important for a philosophical interpretation of aspects of information related to knowledge within an organisation wishing to achieve a competitive advantage by aligning positioning to the cultural aspects of the firm or business. By analysing the completeness of the slightly complex knowledge interpretation processes, identification of interaction between practitioners during knowledge transfer can be identified as having value to the business.

Some would argue however, that a working definition of knowledge for the organisational environment are yet to be established. Authors advise that in addition to no agreed definition of knowledge within management writings, little in the way of commonality can be offered regarding consequent theoretical positioning (Eijkman, 2010; Kalluri \& Kodali, 2014; Marina du, 2007; Zhang, Zhong, \& Makino, 2015). Additionally, (Donate \& Guadamillas, 2015) suggest that problems with knowledge transfer remain prevalent, since in the main, aspects of information related to knowledge is difficult to define, can be ambiguous, unspecific and a dynamic phenomenon (Chen, Li, Hou, Tan, \& Zhu, 2016; Jones \& Holt, 2008). Thompson and Walsham (2004) further stress that because knowledge is a subjective perspective of an individual's experience, associated problems are linked to the context of the knowledge itself. Howells (2002) and (Barnett, Vasileiou, Djemil, Brooks, \& Young, 2011) indicate that an individuals past experiences related to aspects of information related to knowledge can contribute to retaining this knowledge that personal resources may also contribute to this state. As such, many key authors focus on ways to understand and ultimately enhance this knowledge understanding, in a business context, and in doing so, explore various propositions, using occidental foci, derived from historical concepts of: positivism (Green, 2012) (Gates 2001), empiricism (Gupta 2006) and rationalism (Katz 2000).

Thus, this formalised position allows us to highlight doctrines, evident in current theoretical or conditional interpretations (Spohn ,1988) in the context of or surrounding knowledge transfer mechanisms. In doing so, easily relate these to practical and recognisable business environments. For example, leadership, discussed in detail by Storsletten \& jakobsen (2015). From this standpoint, we can then relate interpretation within an aperture of current thinking, 
wherein, theories of reality and change allow the formation of informal axiomatic theories of belief (Godel, 1932; Bull \& Krister 1984), and therefore, remain perpetual or dynamic within a knowledge transfer scenario in a business context. Unquestionably, it is only by analysing the slightly complex processes which combine and surround daily working practices, that useful identification of normative and appropriate interaction between practitioners, during knowledge transfer, can be identified as useful or have value for an organisation. Nevertheless, analogous scrutiny at this point reflects egoistic formations of reality from a knowledge transfer practitioners perception, and can be thought of as a form of cautious belief (Rotaru et al., 2014) of any experience other than that relative to the knowledge transfer scenario. That is, continues to remain analogous to the knowledge transfer practitioner's experiential accounts of aspects of information related to knowledge, but, would be unable to validate the putative distinctive value of aspects of information related to knowledge at a single reference point.

Therefore, we can now understand that examination of aspects of information related to knowledge taxonomy and the types of aspects of information related to knowledge related to business, reveal the complex intertwining with necessary communication scenarios needed to transfer any notion of aspects of information related to knowledge from both an observer and a participating agent or agents frame of reference (Kranjec, 2005). If we accept this posit as aspects of information related to knowledge that is independent of all particular experiences, then it is also equally important to understand the significance of experiential reasoning behind this interpretive position of aspects of information related to knowledge before it is transferred. Whereby, any argument to the contrary would become invalid to either party.

Thus, in this reality, any revision of proposition would result from the relationship between the two axioms and could be interpreted as measurement. We can now argue that this is a natural event, since the practitioners view of knowledge is subjective and assumes any possibly relevant mental states are experiential (Kranjec, 2005). Therefore, we could assume examination of an overriding epistemic principle as a required baseline for success critique. It is easy to understand why this unsophisticated view could be appealing and complete a natural enough answer for knowledge definition. However, this baseline would not relate to both business and personal savannas of existence, since knowledge from this perspective can only exist because someone knows it in his or her mind (Shukla, M., 2015). By definition, knowledge in this form is not an independent entity, which can be transferred, such as information surrounding any material object might be (Shukla, M., 2015). For example, a subject or phenomena within a normal sphere of reality cannot be transferred as knowledge, since it does not exist as independent knowledge. 
We can now agree, plausible extensions and reciprocal elements of classical probability theory which allow interpretation of belief revision(s) and correct probabilistic understanding(s) required by conditional beliefs. Thus, simplification of context or category of meaning, becomes possible, wherein, plausibility tasks or probabilistic events become graded measures (Bennet , 2003). Whereby, allow us to interpret variations of classical belief revision theory, but intercede a multi-agent version. To underpin this unsophisticated, but interpretive stance, our discussion escalates the role and significance of validity (Fascia, 2015), within known knowledge transfer arenas (Argote et al. 2000) as this allows a foundation of significance to dominate any propositional inference. Additionally, it is perhaps unsurprising why interpretive positioning from contemporary writings leads to the view from (Dinur, 2011), who stresses that knowledge is a subjective perspective of an individual's experience, and therefore, associated problems from a business environment are linked to the context of the knowledge itself. Whereby, our discussion assumes an interpretive congruence as an explanatory position, and this central locus becomes key for knowledge interpretation as it provides a valid frame of reference. Importantly, at this juncture, establishment of unsophisticated context or category of meaning allow us to inaugurate boundaries of possibilities and necessities which, would otherwise have remained an overly complex endeavour.

To help us gain an unsophisticated focus regarding this complex phenomena, within this discussion, we suggest that that agent can establish a real time state of validity, that is, an internal locus or state of belief, whereby, all iterations of probability relating to the transfer dilemma remain as valid, only if they are logical along a constant frame of reality. Thus, in this assemble, set $\mathrm{G}$ can assume a classical consequence operation $\mathrm{Cn}$, wherein, the operation of expansion is concurrent with, and only with, the agent's reality frame of reference Kranjec, et al. 2012). Thus, we can deduce that any new information within this reality frame becomes and expansion of set $\mathrm{G}$, (current understanding of all available knowledge), but only from the agents frame of reference (reality). This view in itself becomes understandable if you also consider its interpretation of knowledge from the perspective of (Barnett at al., 2011). Their view indicates that an individual's past experiences related to knowledge can contribute to the retaining of knowledge, and, that personal resources may contribute to the current state of understanding.

\section{Business Context}

To assist with this complex interaction, key elements of emphasis can be drawn from a POPC 
lens approach (Fascia, 2015), since this approach allows a multi view perspective to interweave between individual and group interpretations within a linear frame of reference (Fascia, 2016). This approach allows us to consider that form and location of the knowledge, the indication of knowledge-sharing capability, the relationship between the source and the recipient and the broader environment in which the transfer occurs, are all contributive factors in assessing success (Fascia, 2015). This view now gives the observer a similar frame of reference to the participating agents, whereby, any revision of a proposition within the reference framework allows interpretation from a predicate. Hence, satisfy the necessary axioms, both by contradiction and revision, and at the same time, consider facets of congruence and consistency within the agent's interpretation Kranjec, et al. 2012).

If the position previously discussed is the universal norm within generalist business management theory (White \& Cicmil, 2016), then one could legitimately ask, if the existence of knowledge that in itself depends on the interpretation of a foundational normality is true. Wherein, does the relationship of belief under this premise result from epistemic incongruence by assuming it is either connected on unconnected to the propositional outcome. If this rational intuition were collective, then, all knowledge must derive from a consequence of foundational ethics, which themselves cannot be refuted by accepted moral norms.

This situation is perplexing to say the least and suggests that knowledge of the real world, particularly in a business context, is fallible and multifariously theory laden and allows several options when revising theory with a similar proposition, whereby, a willingness to accept presuppositions which is independent of any evidence. Thus, relating this position to knowledge value in a business context (White \& Cicmil, 2016), it is important to consider the different beliefs asymmetries (Jehn, De Wit, Barreto, \& Rink, 2015) to which practitioners, as human beings, hold in two very distinct ways. These are basic and non-basic. (Lambek \& American Mathematical Society., 2009). Regardless of indifference, there exists agreement within many research streams that organisational knowledge, even in this dissected form, is a recognised source of competitive advantage (Argote and Ingram 2000, p. 156; Storsletten \& jakobsen, 2015) and it is this centralisation of assumption, which can be used to underpin significance in an organisational context. 
Our key focus for this discussion occurs under a POPC lens (Fascia 2015) and allows a multi perspective timeline to interweave between interpretations.

FIGURE 1: POPC lens of interpretation.

The relationship between the source and the recipient.

The form and location of the knowledge.

The source's knowledge-sharing capability.

The broader environment in which the transfer occurs.

SOURCE: POPC THEORY, (FASCIA, 2015)

Assudani (2005) asserts this very clearly by explaining that in this information age, even though knowledge cannot readily be identified on any balance sheet, it is identified as the singularly most valuable asset for a business or organisation. Therefore, the interpretive praxis for knowledge schema could be debated at length as there is no such thing as "normal knowledge'. This discussion must therefore must consider how knowledge viewpoint fits within the interpretive theoretical overview and the formalised description of business management, however writings on this subject is extremely diverse and non definitive. Knowledge itself is difficult to define and some authors baulk at the prospect of definition. Davenpoet et al. 1998:43) quoted Boulding (1966:1)

"considering the difficulties of defining, catogorising and measuring knowledge, One feels that the efforts to do so lead into a philosophical mess from which the only escape is to climb out, clean ones self off, go home, have a dinner and forget all about viewpoint".

However, for this study and in the spirit of understanding knowledge and viewpoint, this section will examine why it is important to discover, where knowledge is philosophically positioned in relation to a business context. It is also equally important to understand the significance of experiential reasoning behind this interpretive position of knowledge before it is transferred. Important because, the adaptation by the knowledge transfer practitioners involved purport to a position of justification in the transfer schema.

Thus, discussion and examination of an overriding epistemic principal is required as a baseline for further critique of related writings. Therefore knowledge taxonomy and the types of 
knowledge related to business are discussed along with the necessary understanding of communication to transfer any notion of knowledge. Scrutiny at this point reflects egoistic conceptions of this reality from a knowledge transfer practitioners perception or cautious belief of any experience other than that relative to the knowledge transfer scenario. This is because knowledge transfer practitioners experiential accounts of knowledge would be unable to explain the putative distinctive value of knowledge. Since the practitioners view of knowledge is subjective, any possibly relevant mental states are experiential.

Boulding (1966) describes knowledge as images related to cognitive content. As such, Knowledge from this perspective, can only exist because someone knows it in his mind, it is not an independent entity to be transferred, such as any material object might be. For example, a chair cannot be transferred as knowledge, it is not a knowledge. In an attempt to reconcile these anomalies studies by (Szulanski 2000, p. 10) defines knowledge as a 'causally ambiguous set of routines'. However, one could ask if the existence of knowledge, that in itself depends on the interpretation of a foundational normality is true, then all knowledge must derive from a consequence of foundational ethics which in themselves cannot be refuted by accepted moral norms. This situation is a perplexing situation to say the least. Sayer (1984) affirm this, stating that our knowledge of that real world is fallible and theory laden. It exists but our knowledge of it is unclear, is singular in its focus and can also suffer from borrowed interpretations covering many disciplines, which belie the potentials inherent in other focused research directions.In this sense, cognitive interpretations of knowledge vary, are often very broad or very non-specific. For example (Nonaka 1994 p.34) maintains that a distinction can often made between data, information and knowledge. Conversely (Castaneda 2000, p. 3) define Knowledge as an 'elusive concept' and (Nonaka 1994 p. 15) described knowledge as 'a multifaceted concept with multi-layered meanings'. In an attempt to bring some clarity to the matter Berger and Luckmann (1967) give a broad example of definition as: "the certainty that phenomena are real and that they possess specific characteristics" (p.13).

Nonetheless, because of the philosophical diversity surrounding the theoretical base of knowledge definition, research conclusions form many incongruities and variations. According to Tell (2004), even the overall characterisation of knowledge, which encompasses the tacit and explicit dimension, has so far been too unsophisticated. Yet, regardless of this indifference, there still exists agreement within many research streams that organisational knowledge in this dissected form, is a source of competitive advantage (Argote and Ingram 2000, p. 156). 
Additional research with a similar focus highlights that knowledge has been further stipulated in other categorical instances as: organisational manufacturing capabilities (Zander and Kogut 1995); assets (Spender 1996); innovation (Rogers 1995) and best practices (Szulanski 1996). Grant (1996b, p. 110) underlines the difference between conflicting opines by declaring that knowledge is 'that which is known'.

\section{Philosophical Impost}

From a philosophical position in Occidental society, the understanding of knowledge can generally be regarded as falling between two arguments, the first is Rationalism (Descartes 1644, Leibniz 1673, Kant 1787) which postulates that a proposition can be known from reason alone without the need for, or indeed independent from, experience. In the context of this discussion, it is also important to recognise the impressions of Spinoza (See A TheologicalPolitical Treatise 1670) since complimenting the rationalist connection, Spinoza contended that "God" and "Nature" were the same reality, namely a singularity that underlies the universe and everything else was simply modes or modifications. He contended that "Deus sive Natura" ("God or Nature") was of infinite attributes, hence, his account of reality was to understand physical and mental worlds as two different, parallel "subworlds", which neither overlap nor interact.The second is Positivism (see Aristotle, Berkeley 1710, Hume 1739), which postulates that propositions can only be known directly from experience. It is also important to mention logic according to Kant's definition: Our knowledge springs from two fundamental sources of the mind; the first is the capacity of receiving representations (receptivity for impressions), the second is the power of knowing an object through these representations spontaneity in the production of concepts. (see Kant 1781; 1787).

Thus, relating this philosophical knowledge position to knowledge value, it is important to consider these different asymmetries, which deliberately assume human beings hold beliefs in two distinct ways. Basic and non-basic. Hence, non-basic beliefs are based on other beliefs by interference, for example 'I believe that all green apples are sweet', is based on my inference that 'all apples are sweet'. Basic beliefs, are of course not, for example 'I believe that I am sitting in front of this computer, writing this discussion', is based on my experience I am having right now, not by inference of some other belief. Clearly, there is a fundamental problem in aligning these posits, regarding their usefulness in proposing underpinning knowledge values or even corrective knowledge transfer axioms. Since, both positional inferences, presuppose an assumption regarding cognitive psychology, in that, they both require interpretive 
associations regarding knowledge. Hence, they inextricably link knowledge and knowledge transfer as a cognitive process. From this dual philosophical standpoint, it is important at this point to acknowledge the subject groups cultural background, which will be apparent in the research data collection. It is also important to note that one of the few alternate ideologies capable of challenging and transcending prevailing knowledge transfer streams is Islam. This is because, this philosophical position or what is sometimes referred to as fundamentalist position, possesses a repertoire of powerful symbols and subsequent organisational approaches readily adaptable to political science in an occidental context. However, as an academic opinion, this is very important for this discussion, since if I endorse this axiom then I can endorse both hermeneutics and foundationalism. This is important as I can therefore begin to approach epistemological issues regarding the definition of knowledge and knowledge value from a pragmatic centre, which otherwise may escape me in this research.

If we are now able to consider this duality of proposition as a single entity, that is, to what extent can alignment be validated, in a way that supports corrective knowledge transfer axioms (Jiang, Colakoglu, Lepak, Blasi, \& Kruse, 2015), then it becomes a very useful perspective indeed. This is because both positional inferences presuppose an assumption, in that, they both require interpretive associations from the actors to legitimise any validity regarding knowledge, and thus, inextricably link knowledge and knowledge transfer as the same cognitive process (Kranjec, 2005).

That is, differing actions align to differing options or operators of necessity, and not simply interpretations of fallible and defeasible evidence as experiential/nonexperiential. This is an important position to adopt, as we can now approach epistemological issues regarding the definition of knowledge and knowledge value from a pragmatic centre. However, we first need to be able to adopt an axiomatic starting point (Jiang et al., 2015) and epistemic principle from which to define knowledge from multiple perspectives. The benefit from this interpretation is clear, that is, if we endorse this axiomatic positioning, then we can endorse both hermeneutics and foundationalism as a generality norm or singularity. That is, it becomes dynamic. Whereby, the represented states of external reality of the observer assume the agents position as not part of the observers reality frame. Whereby, the agent's dispositions do not align to his beliefs. Thus, his actions or change, cannot effect any part of any external reality.

In this case, we can now draw from definition by (Feenstra, 1988) and (Ahmad \& Daghfous, 2010), whereby, knowledge must consist, at least to a large extent, in a clarification of value 
which does not consist in definition alone, and therefore, must possess a systemic for such clarification using epistemic principle. As such, we can now agree that knowledge from this multivariate perspective exists as a combined state, but our awareness of it remains unclear, is singular in focus and suffers from borrowed interpretations covering many disciplines. In this sense, we can now understand why, although numerous in number, most theoretical interpretations belie the potentials inherent in focused research. Wherein, most attempts to categorise a temporal state for knowledge end up as a lateral presumption which, by its very nature, attempts to coexist with cognitive interpretations of knowledge. Therefore, it is easy to see why interpretations inevitably vary, are very broad and where non-specific boundaries and parameters pillory most, if not all, indices of symptomatic validity. To fully debate, this point would be extensive to say the least, however in the caveat of a business context, we can say that a philosophically identifiable position of knowledge is a phenomenon, which may be experienced as a temporal dimension, but has to be justified as a true belief before it can be termed valuable. Similarly, in this case, the construct of our knowledge is parallel to doxastic attitude as discussed previously. In this discussion, we can accept that from a business context, when conceiving as a faculty for distinguishing between truth and falsity, any experiential decision that would lack the cognitive status, traditionally ascribed, and therefore would be considered a priori false. Accordingly, from the standpoint of knowledge value, it is important to consider the evidence of this knowledge when deciding if it is true or not. As such, does the knowledge itself need to be better understood before it can be successfully transferred or is it simply empirical cogency, which has been transferred.

Clearly, from a business context, this involves philosophical support by paradigms and archetypes overarching business activity and relating to business success, but thereby giving knowledge 'value' by this premise alone and not as a justification of any other epistemic principle.

Dealing with these difficulties has led to the construction of two diametrically opposed views subjugated from an occidental perspective on the nature of Islamic viewpoint versus occidental viewpoint. The most influential view is that which stems from the work of Leo Strauss (1959), and which represents Islamic viewpoint as having a great deal to hide in their writings. I think it is important to note that although Strauss espoused the utility of religious belief, there is some question about his views on its value, considered intemperate and irrational (See Strauss 1995, Political Science and Politics). Strauss continues that this philosophical position is taken 
to be involved in the skilful dissimulation of their genuine irreligious and Greek-inspired opinions. Further, it is done in such a way that their fellow thinkers would follow their arguments to their logical conclusion. While more modest intellects would be satisfied that they were in the presence of theories acceptable to Islam. The identification of underpinning Islamic philosophical axioms related to this argument can be attributive to many authors but none more so than Al-Ghazzali (See Choudhury,1997) Al-Ghazzali writings span at least 400 volumes. A central objective or caveat of Al-Ghazzali in all his writings was the unity of knowledge, rooted in the Oneness of God, as the path for all moral concepts, ultimately, leading to the belief in God. Philosophically, this view is remarkably similar to Kant (see Kant ' 1781 a critique of pure reason') for whom reason was the categorical imperative of freedom and free will. Kant, however, believed that it was a clear exposition of morality which led to belief in God. Importantly, in relation to knowledge, at the centre of Ghazzali's ideal state is the individual with a spiritual as well as a social personality. Clearly, this Islamic concept of an individual within a spiritual social community sharply contrasts with Occidental self-centred and profit driven economics. From a philosophical perspective no such annulment is possible in Islam. Thus, from an Islamic philosophical perspective, analytically, the central logic of occidental economics is that knowledge has value as a resource capture for profit-driven capitalism. Resource capture here is by means of capitalisation (Mehmet 1995, pp. 25-9) and subsequently adds that over time, all non-capital resources will be transformed into new forms of capital. Natural resources would therefore become ecological assets, knowledge. In summary, knowledge value from this perspective, viewed as intellectual is for a singular point 'for profit'. However, if one were to adjudicate a philosophical position at this point one could ask, is it possible to extend epistemic knowledge of these principals . That is, to make these concepts themselves precise and to gain comprehensive and secure insight about the fundamental relations that are present among them, moreover, the axioms that hold for them.

\section{Epistemic Principal}

Hence, to be able to adopt a philosophical starting point regarding an epistemic principal from which to define knowledge. Knowledge, from both perspectives it seems, must consist, at least to a large extent, in a clarification of knowledge value, that does not consist in definition alone, and therefore must possess a systemic for such a clarification using an epistemic principal. To fully debate this point would be extensive to say the least, however in the caveat of knowledge transfer, in a business context, the understanding of complex interactions of philosophical 
positions agrees with the premise suggested by Drucker et al. This is an essential underpinning to business success and competitive advantage, and warrants further investigation outwith this discussion. The philosophically identifiable positions of knowledge at this point can state that any knowledge can be experienced, but has to be justified as a true belief before it can be termed knowledge. Similarly, to assume any value or relevance to the sender or receiver of it the acceptance of the tripartite theory of knowledge, Belief, Truth and Justification (epistemic principal) must also be inferred. It is important, at this juncture to also distinguish between truth and perceived truth in the context of the knowledge experience relating to knowledge value. For example, when conceiving as a faculty for distinguishing between truth and falsity, any experiential decision that would lack the cognitive status, traditionally ascribed, would be considered false (See, Blackburn 1987; Craig 1985; Wright 1989). Accordingly, from the standpoint of knowledge value, it is important to consider the evidence of this knowledge when deciding if it is true or not, on the basis that the knowledge itself has to be better understood before it can be transferred or if it is simply the empirical cogency that has been transferred. To allow a pragmatic approach to understanding value of knowledge as a 'thing' that has to be transferred, the axiological foundationalism significance of the human perception of knowledge would appear to be a significant contributing factor. Similarly the construct of our knowledge is parallel to doxastic attitude as discussed previously. Through reconciliation of foundational and doxastic positions, one can now view knowledge and knowledge value as a singular construct, although this can now be characterised through a multitude definition but not as a singular epistemic principal.

As a precursor to many theoretical positions based on philosophical precedence, Winter (1987) identified four succinct knowledge dimensions which would enhance this capability to position knowledge relative to a personal interpretation: tacit vs articulable; not observable vs observable in use; complex vs simple; and dependent vs independent of a system. Zander and Kogut (1995) developed constructs of knowledge into five distinguishable parts: codifiability; teachability; complexity; system dependence; and observability. Additionally, Grant (1996) regards knowledge into two separate categories: knowing about (covering facts, theories and sets of instructions) and knowing how (involving skills that are expressed through performance). This development of knowledge construal's allowed (Blumentitt and Johnston 1999) to further identify knowledge into four, perhaps common sense, categories; Codified Knowledge, Common Knowledge, Social Knowledge, Embodied Knowledge. Davenport's and Prusak (1998) define knowledge as: "Knowledge is a fluid mix of framed experience, 
values, contextual information, and expert insight that provides a framework for evaluating and incorporating new experiences and information. It originates and is applied in the minds of the knowers. In organisations, it often becomes embedded not only in documents or repositories but also in organisational routines, processes, practices, and norms" (p.5). Coakes and Sugden (2000) explain that these and other theorists have discussed: declarative knowledge (knowledge about something -a shared understanding of concepts, categories); procedural knowledge ( knowledge of how something happens); and causal knowledge (knowledge of why something happens and can thus enable strategy formulation). Kalling and Styhre (2003), knowledge is emerged when information is placed in a particular context, and is often associated with a specific persons thoughts and actions that are influenced by their values and beliefs. Knowledge may be discussed from many philosophical and theoretical positions and could be classed as multi-faceted as previously defined. What is clear from this discussion is that knowledge, in whatever proximity its understanding is derived from, is easier to position in terms of value if it is first categorised. This categorisation of two types of knowledge which can be related to a business context, in terms of this discussion at least, will fall into either Tacit or Explicit knowledge.

This perspective indicates that investigation and understanding of knowledge is important, since at its core, the study of knowledge transfer is concerned with the process of moving useful knowledge from one place to another. A problem, from a philosophical perspective confuses this issue, in that, if it is difficult to define the experiential primitives, such as personal experience, then it will be equally difficult to define the primitive concepts of knowledge. For example, Castaneda defines Knowledge as an 'elusive concept', and many others have had their say on the subject without definitive conclusion. ( See Descartes 1644 , Leibniz 1673 , Kant 1787, Aristotle , Berkeley 1710 , Hume 1739 ). Thus, the question of why knowledge is more valuable than mere true belief, is really why issue of why knowledge is more valuable than any proper subset of its parts. That is, does an actor specifically desire knowledge rather than any epistemic standing. The importance of this distinction between the two value problems is seen by considering that in some cases justification adds value to a mere true belief not to the knowledge. If this last point is right, then one might reasonably argue that the fact that knowledge entails justification since there would now be a property of knowledge which mere true belief lacks and which affords greater value to knowledge over mere true belief. This discussion would argue however, if an actor in this position would thereby have an understanding of justified true belief. Then the account of the value of knowledge ended at this 
point. Thus the epistemic value is of a justified true belief and not of the knowledge nor the sum of its parts. Undoubtedly, this adds to the misunderstanding regarding any knowledge definition and any subsequent analysis or research therein. It is therefore surprising that such anomalies are considered almost redundant when enthusiastic interpretations of knowledge in a business context (Blackler,1995; Badaracco 1991; Winter 1987, and others) are debated at length. In this sense, the writings purports one fundamental assumption regarding the philosophical position of knowledge, that, if given the correct circumstances and understanding, knowledge and its value can be created and universally transferred, unproblematically. Szulanski and Jensen for example, regard knowledge as an 'instantaneous process'. While Blumentitt and Johnston (1999) surprisingly add that, 'information gains further value when it is used in new contexts .... and is transformed into enterprise specific knowledge in the process' This philosophical position being the case, it is easy to understand why knowledge would be deemed a useful resource to a business of firm even without proper conceptual understanding of its nature and perhaps content or understanding. Consequently, many theorists focus their attention on this line of reasoning, and support justification for their research with pre conceived understanding relating to knowledge transfer practitioners influencing effectiveness of knowledge transfer, in a business context. Similarly, its ultimate efficiency, underlining communication as an all incumbent sub set of functions(See Kogut and Zander 1996) There is also a unified acknowledgement that there are conditions under which knowledge transfer experience gained by one unit can enhance or hinder knowledge creation in another unit (Darr, Argote, and Epple 1995; Argote, Ingram). Thus, suggesting the characteristics of knowledge acquired by one actor affect knowledge creation in another one. But, as there is still a disunity in the exact definition of knowledge, Szulanski defines knowledge as a 'causally ambiguous set of routines', this seems to contradict the previous paragraph as to why a focus on something that is misunderstood exists in the first place. This is especially significant since according to Blumentitt and Johnston (1999) the recipient of knowledge needs to have a cognitive understanding of it for it to be useful. Although ultimately confusing, this is a very important and perhaps critically recurring point throughout the writings from a philosophical perspective. It determines that the extended route of knowledge in a transfer scenario, the knowledge is not regarded as an invariable or singular concept. Though ultimately significant, throughout the philosophical positioning within the writings, it is the transfer parameters which adopt the focus of prioritised importance and not the definition of the knowledge being transferred. This position of knowledge understanding and communication is in itself derived from a sequence of parameters which are classified from a 
philosophical position of justifiable truth and belief. Although Sayer (1984) argues that knowledge of that real world both fallible and theory laden. Thus, if this philosophical perspective reflects the locus of knowledge understanding, then one can conclude that the philosophical perspective of the knowledge to be transferred will also be derived from these unclear epistemological milieus. Therefore, in summary, from the majority of the writings, the theoretical ingredients or constituent parts of knowledge are understandably from a primarily occidental philosophical perspective. ( See Descartes 1644 , Leibniz 1673 , Kant 1787, Aristotle , Berkeley 1710 , Hume 1739 ). Conversely however, the central tenet regarding Islamic understanding of knowledge was the unity of knowledge is simply rooted in the Oneness of God (See Al-Ghazzali, Choudhury 1997). Thus, the Occidental perspective, which is prominent in mainstream writings, involves philosophical support by paradigms and archetypes of knowledge as discussed in this chapter. Thus, any epistemic principal, overarching business activity and relating to business success, gives knowledge 'value' by this occidental premise alone and not as a justification of any other epistemic principal. 


\section{CONCLUSION}

This discussion has focused on outlining and assessment of current and historical knowledge viewpoint, theory and positioning, but at the same time, places it within the realms of a business context. It concentrated on the epistemic principal of knowledge. The writings in this section indicated that the epistemic principal of knowledge is important as at its core the study of knowledge transfer is concerned with the process of moving useful knowledge from one place to another. However the writings concludes that at present there is no consolidated definition of knowledge in a business context .... or any other for that matter. Therefore, in the next chapter, the interaction of epistemic knowledge principal from a knowledge transfer practitioners point of view is examined. This will identify if there are any alternative perspectives to knowledge and knowledge transfer posited from mainstream business management writings, specifically relating to underpinning business practices, success and competitive advantage .

\section{REFERENCES}

Barnett, J., Vasileiou, K., Djemil, F., Brooks, L., \& Young, T. (2011). Understanding innovators' experiences of barriers and facilitators in implementation and diffusion of healthcare service innovations: a qualitative study. BMC Health Services Research, 11, 342. doi:http://dx.doi.org/10.1186/1472-6963-11-342

Chen, Y., Li, F., Hou, B., Tan, S., \& Zhu, H. (2016). Convergence analysis of discrete-time consensus algorithm with both self and transmission delays. Journal of the Franklin Institute, 353(11), 2467-2481. doi:10.1016/j.jfranklin.2016.05.001

Donate, M. J., \& Guadamillas, F. (2015). An empirical study on the relationships between knowledge management, knowledge-oriented human resource practices and innovation. Knowledge Management Research \& Practice, 13(2), 134-148. doi:http://dx.doi.org/10.1057/kmrp.2013.36

Eijkman, H. (2010). Academics and Wikipedia. Campus - Wide Information Systems, 27(3), 173-185. doi:http://dx.doi.org/10.1108/10650741011054474

Green, M. (2012). Objectivism in organization/management knowledge: an example of Bourdieu's "mutilation"? Social Responsibility Journal, 8(4), 495-510.

Jehn, K. A., De Wit, F. R. C., Barreto, M., \& Rink, F. (2015). Task conflict asymmetries: effects on expectations and performance. International Journal of Conflict Management, 26(2), 172. 
Jiang, Y., Colakoglu, S., Lepak, D. P., Blasi, J. R., \& Kruse, D. L. (2015). Involvement work systems and operational effectiveness: Exploring the moderating effect of national power distance. Journal of International Business Studies, 46(3), 332-354. doi:http://dx.doi.org/10.1057/jibs.2014.61 Jones, O., \& Holt, R. (2008). The creation and evolution of new business ventures: an activity theory perspective. Journal of Small Business and Enterprise Development, 15(1), 51-73.

Kalluri, V., \& Kodali, R. (2014). Analysis of new product development research: 1998-2009. Benchmarking, 21(4), 527-618. doi:http://dx.doi.org/10.1108/BIJ06-2012-0040

Lambek, J., \& American Mathematical Society. (2009). Lectures on rings and modules. Providence, RI: AMS Chelsea Pub.

Marina du, P. (2007). Knowledge management: what makes complex implementations successful? Journal of Knowledge Management, 11(2), 91101. doi:http://dx.doi.org/10.1108/13673270710738942

White, G. R. T., \& Cicmil, S. (2016). Knowledge acquisition through process mapping. International Journal of Productivity and Performance Management, 65(3), 302-323. doi:10.1080/14783363.2015.1044892.

Zhang, X., Zhong, W., \& Makino, S. (2015). Customer involvement and service firm internationalization performance: An integrative framework. Journal of International Business Studies, 46(3), 355-380. 